\title{
Energy expenditure and substrate metabolism in patients with cirrhosis of the liver: effects of the pattern of food intake
}

\author{
W P H G Verboeket-van de Venne, K R Westerterp, B van Hoek, G R Swart
}

\begin{abstract}
Patients with liver cirrhosis are often undernourished. In healthy subjects, the pattern of food intake is one of the variables that can influence energy balance and substrate metabolism. The short term (two day) effect of the pattern of food intake in patients with cirrhosis and controls was compared. In a respiration chamber, eight patients with cirrhosis of the liver and 23 controls were fed to estimated energy balance in two meals daily ('gorging' pattern) and four to seven meals daily ('nibbling' pattern). Twenty four hour energy expenditure, expressed as a multiple of the sleeping metabolic rate, was reduced in patients with cirrhosis $(1.31(0.03) v 1.44(0.02)$ for controls; $p<0.01)$ because of an increased sleeping metabolic rate per $\mathrm{kg}$ fat free mass in these patients. In both patients and controls, the respiratory quotient was significantly lower during the morning preprandial period $(9.00-12.00)$ on the gorging pattern, reflecting a higher oxidation ratio of fat to carbohydrate compatible with a more catabolic state. For patients with cirrhosis, a nibbling pattern of food intake, including a good breakfast and a late evening meal, would be preferable, in order to have shorter episodes of catabolism during the day.

(Gut 1995; 36: 110-116)
\end{abstract}

Keywords: cirrhosis, food intake, energy balance, substrate metabolism.

Department of Human Biology, University of Limburg, Maastricht W P H G Verboeket-van de Venne

K R Westerterp

Department of Gastroenterology/ Hepatology, University Hospital, Maastricht

B van Hoek

Department of Internal Medicine II, University Hospital

Rotterdam,

The Netherlands

G R Swart

Correspondence to:

Dr W Verboeket-van de

Venne, Department of

Human Biology, University

of Limburg, PO Box 616 ,

6200 MD Maastricht,

The Netherlands.

Accepted for publication

21 April 1994 Assessment of energy expenditure and substrate metabolism in patients with cirrhosis of the liver is important to explain the combination of processes that leads to malnutrition in these people. Information on energy expenditure measurements in patients with cirrhosis has been inconsistent. Some studies have reported an increased resting metabolic rate in cirrhotic patients, ${ }^{1-4}$ while others have described a normal ${ }^{56}$ or low rate. ${ }^{17}$ Part of this variation may be a result of the different methods used for measuring and calculating energy expenditure. In a study by Nielsen et $a l,{ }^{8}$ five malnourished patients with cirrhosis were fed increasing amounts of food for a mean of 42 days. Measured 24 hour energy expenditure, determined by the doubly labelled water technique, was about $18 \%$ higher than the calculated 24 hour energy expenditure. Müller et $a l,{ }^{9}$ examining energy expenditure and substrate metabolism in a large group of patients with cirrhosis $(n=123)$, reported that $18 \%$ were considered hypermetabolic, whereas $52 \%$ were normometabolic, and $31 \%$ were hypometabolic. They concluded that the resting metabolic rate is not a clear cut phenomenon in cirrhotic patients. Owen et $a l^{5}$ reported that after an overnight fast the energy requirements of patients with alcoholic cirrhosis were normal, but the nature of fuels oxidised was more similar to that in healthy controls after two to three days of total starvation, that is, a relatively high contribution of fat to energy metabolism.

The pattern of food intake is often cited as one of the variables that can influence energy balance and substrate metabolism. When the daily energy intake is consumed in a small number of large meals ('gorging' pattern) relatively more energy has to be stored than with a feeding pattern of a large number of small meals ('nibbling' pattern). A gorging pattern has been shown to enhance lipogenesis, ${ }^{1011}$ to increase body weight, ${ }^{12}$ to increase the blood serum cholesterol concentration, ${ }^{13} 14$ and to reduce glucose tolerance. ${ }^{14-16}$ In a previous study in which we investigated the short term (two day) effect of feeding frequency on nutrient utilisation in healthy young subjects, we observed a stronger diurnal periodicity of lipogenesis and lipolysis on a gorging pattern than on a nibbling pattern of food intake. ${ }^{17}$ In patients with cirrhosis of the liver, a late evening meal seemed to improve the efficiency of nitrogen metabolism. ${ }^{18}$

This study was conducted to assess the

\section{SUBJECTS}

Eight patients with biopsy-proved cirrhosis of the liver were studied. All were in a stable clinical condition at the time of the study. Their median age was 53 (range 39-62) years and their median body mass index was $23 \cdot 7$

\section{Methods}


TABLE I Characteristics of the patients with cirrhosis of the liver

\begin{tabular}{llllllllll}
\hline $\begin{array}{l}\text { Case } \\
\text { no }\end{array}$ & Sex & $\begin{array}{l}\text { Age } \\
(\mathrm{y})\end{array}$ & $\begin{array}{l}\text { Body mass } \\
\text { index } \\
\left(\mathrm{kg} / \mathrm{m}^{2}\right)\end{array}$ & Diagnosis & $\begin{array}{l}\text { Alanine } \\
\text { aminotransferase } \\
\text { (Un) }\end{array}$ & $\begin{array}{l}\text { Alkaline } \\
\text { phosphatase } \\
(\text { Un) })\end{array}$ & $\begin{array}{l}\text { Bilinubin } \\
(\mu \mathrm{molh})\end{array}$ & $\begin{array}{l}\text { Albumin } \\
(\mathrm{g} / \mathrm{l})\end{array}$ & $\begin{array}{l}\text { Child-Pugh } \\
\text { classification }\end{array}$ \\
\hline 1 & M & 46 & $20 \cdot 6$ & Alc & 25 & 104 & 11 & 47 & B \\
2 & M & 49 & $26 \cdot 8$ & Alc & 28 & 52 & 7 & 40 & A \\
3 & M & 39 & $23 \cdot 1$ & PSC & 55 & 169 & 9 & 39 & A \\
4 & M & 49 & $24 \cdot 4$ & PSC & 80 & 702 & 60 & 28 & B \\
5 & F & 56 & $27 \cdot 7$ & PSC & 41 & 499 & 78 & 37 & B \\
6 & F & 61 & $23 \cdot 2$ & AICAH & 37 & 109 & 7 & 32 & A \\
7 & F & 62 & $24 \cdot 2$ & PBC & 54 & 379 & 33 & 28 & B \\
8 & F & 58 & $22 \cdot 0$ & Crypt & 28 & 467 & 49 & 20 & B \\
\hline
\end{tabular}

$\mathrm{Alc}=$ alcoholic cirrhosis; $\mathrm{crypt}=\mathrm{cryptogenic}$ cirrhosis; $\mathrm{PSC}=$ primary sclerosing cholangitis; $\mathrm{AICAH}=$ autoimmune chronic active hepatitis with cirrhosis; $\mathrm{PBC}=$ primary biliary cirrhosis.

(range $20 \cdot 6-27 \cdot 7$ ) $\mathrm{kg} / \mathrm{m}^{2}$. Further details are shown in Table I. The median age of the healthy adult controls $(10 \mathrm{men})^{19}$ was 41 (range 25-61) years and their median body mass index was $24 \cdot 7$ (range $20 \cdot 7-30 \cdot 4$ ) $\mathrm{kg} / \mathrm{m}^{2}$. The healthy young adults (two men, 11 women) $)^{17}$ had a median age of 20 (range 18-23) years and a median body mass index of 20.6 (range $18 \cdot 4-26 \cdot 1$ ) $\mathrm{kg} / \mathrm{m}^{2}$. The research protocol was reviewed and approved by the local ethical committee. The procedures to be used in the study were carefully explained to the subjects before they gave their written consent to participate.

\section{EXPERIMENTAL DESIGN}

The experiment consisted of two periods of two consecutive days. During one episode of two days, patients consumed two meals (gorging pattern), and during the other episode of two days they had four meals (nibbling pattern). The order of administration of the gorging and nibbling patterns was randomised. Subject 4 was studied only during the nibbling pattern, and subject 8 only during the gorging pattern. The interval between the two experimental periods was at least five days. On the first day of each period the patients came to the University of Limburg in Maastricht to stay in a respiration chamber for \pm 44 hours. Oxygen consumption, carbon dioxide production, and hence the respiratory quotient and energy expenditure were the main measurements (see below). Urine samples were collected to determine nitrogen excretion and hence to calculate the non-protein respiratory quotient and substrate oxidation. Patients were fed to an estimated energy balance assuming 24 hour energy expenditure to be $1 \cdot 38 \times$ basal metabolic rate. The basal metabolic rate of the patients was calculated according to the equations of Harris and Benedict, ${ }^{20}$ based on the sex, age, height, and weight of the patients.

TABLE II Energy metabolism in patients with liver cirrhosis $(n=8)$ and healthy adult subjects $(n=10)$. Data are expressed as mean (SEM)

\begin{tabular}{lcc}
\hline & Liver cirrhosis patients & Healthy adults \\
\hline 24 h energy expenditure (EE) $(\mathrm{kJ} / \mathrm{d})$ & $9105(519)$ & $9365(210)$ \\
Sleeping metabolic rate $(\mathrm{SMR})(\mathrm{kJ} / \mathrm{d})$ & $6971(418)$ & $6528(147)$ \\
24 h EE/SMR & $1 \cdot 31(0 \cdot 03)^{\star \star}$ & $1 \cdot 44(0 \cdot 02)$ \\
SMR/body mass $\left(\mathrm{kJ}^{-\mathrm{kg}^{-1}} \cdot \mathrm{d}^{-1}\right)$ & $99 \cdot 2(4 \cdot 9)^{\star}$ & $86 \cdot 4(3 \cdot 3)$ \\
SMR/fat free mass $\left(\mathrm{kJ}^{-1} \cdot \mathrm{kg}^{-1} \cdot \mathrm{d}^{-1}\right)$ & $127 \cdot 1(4 \cdot 5)^{\star \star}$ & $112 \cdot 3(2 \cdot 0)$ \\
SMR as a \% of basal metabolic rate & $112 \cdot 2(5 \cdot 5)^{\star \star}$ & $91 \cdot 7(2 \cdot 2)$
\end{tabular}

Statistical significance $v$ healthy adults: ${ }^{\star \star} \mathrm{p}<0.01,{ }^{\star} \mathrm{p}<0.05$.

SMR/BM, sleeping metabolic rate per kg body mass; SMR/FFM, sleeping metabolic rate per kg fat free mass.
EATING PATTERNS

The two eating patterns were characterised by a minimal or maximal spreading of the energy intake throughout the day. The gorging pattern consisted of two large meals: at $12.00 \mathrm{a}$ lunch containing $50 \%$ of the daily energy intake and at 18.00 a dinner containing the remaining $50 \%$. The nibbling pattern consisted of four smaller meals: at 7.30 a breakfast (20 energy \%), at 12.00 a lunch (30 energy \%), at 18.00 a dinner ( 30 energy $\%$ ), and at 22.30 an evening snack ( 20 energy $\%$ ). The patients were instructed to consume all food items and to return any left overs. The total daily energy intake was the same for the two feeding patterns with the same menu and macronutrient composition. The food provided 12 energy $\%$ protein, 38 energy \% fat, and 50 energy \% carbohydrate. The value of the food quotient as defined by Flatt ${ }^{21}$ was $0 \cdot 86$.

\section{PROCEDURES}

Body mass and body composition

Patients weighed themselves (without clothing) in the morning of days 2 and 3 upon rising, after voiding, and before any food/ drink consumption, on a digital balance (Seca delta, model 707 ) accurate to $0 \cdot 1 \mathrm{~kg}$. Body composition was measured by deuterium dilution on the first evening of the stay in the respiration chamber. Before going to bed at night on day 1 between 22.30 and 23.00, a ${ }^{2} \mathrm{H}_{2} \mathrm{O}$ dilution was drunk after emptying the bladder (baseline urine sample). The dosage calculation was based on body mass in order to create a ${ }^{2} \mathrm{H}$ excess of $100 \mathrm{ppm}$. A second urine sample was collected by the patients on day 2 , in the morning after the first voiding between 8.00 and 10.00 . Isotope abundances in the urine samples were measured with an isotope ratio mass spectrometer (VG Isogas, Aqua Sira). Total body water was calculated as the measured deuterium dilution space divided by $1 \cdot 04 .^{22}$ Fat free mass was calculated as total body water $/ 0.73$; fat mass was calculated as body mass minus fat free mass.

\section{Urinary nitrogen excretion}

Urine was collected in six portions: from $18.00-23.00$ on day 1 , from 23.00 on day 1 to 7.00 on day 2 , from $7.00-12.00$ on day 2 , from $12.00-18.00$ on day 2 , from $18.00-23.00$ on day 2 , and from 23.00 on day 2 to 7.00 on day 3. Samples were collected in containers 
with $2 \mathrm{ml} \mathrm{H}_{2} \mathrm{SO}_{4}$ to prevent nitrogen loss through evaporation; volume and nitrogen concentration were measured subsequently, the latter using a Heraeus analyser (type CHN-O-Rapid).

\section{Respiration chamber measurements}

Oxygen consumption and carbon dioxide production were measured in a respiration chamber. ${ }^{23}$ This chamber measures $14 \mathrm{~m}^{3}$ and is furnished with a bed, chair, table, TV, radio, telephone, wash-bowl, and toilet facilities. The chamber is ventilated with fresh air at $50 \mathrm{l} / \mathrm{min}$. The ventilation rate was measured with a dry gasmeter (Schlumberger, type G6). The concentrations of oxygen and carbon dioxide were measured with a paramagnetic oxygen analyser (Servomex, type OA 184) and an infrared carbon dioxide analyser (Hartman \& Braun, type URAS 3G). Incoming air was analysed once every 15 minutes and outgoing air once every 5 minutes. The gas sample to be measured was selected by a computer, ${ }^{23}$ which also stored and processed the data. The respiratory quotient and energy expenditure were calculated from oxygen consumption and carbon dioxide production. ${ }^{24}$ Subjects went to bed at 23.00 and rose at 7.00. During daytime they were allowed to move freely, to sit, lie down, telephone, listen to the radio, and watch television, only sleeping and strenuous exercise were not allowed.

\section{ANALYSIS OF DATA}

Twenty four hour energy expenditure and the respiratory quotient were calculated from 7.00 to 7.00. Energy balance was determined by subtracting the 24 hour energy expenditure from energy intake. The sleeping metabolic rate was measured from 3.00 to 6.00 , when subjects were asleep. To describe the effect of feeding frequency on substrate oxidation, the respiratory quotient was calculated over three hour intervals throughout the day. Urinary nitrogen excretion was determined for the same intervals, taking into account the different collecting periods. Protein, fat, and carbohydrate oxidation were calculated according to Jéquier et al. ${ }^{25}$ The effects of feeding frequency on the diurnal pattern of respiratory quotient, non-protein respiratory quotient, and substrate oxidation were analysed by repeated measures analysis of variance (ANOVA) and Scheffé $F$ tests. Differences between the gorging and nibbling patterns were tested using unpaired $t$ tests. In the text, tables, and figures, data are presented as the mean (SEM).

\section{Results}

ENERGY BALANCE

Garrow $^{26}$ stated that adult subjects are in energy balance when the difference between energy intake and energy expenditure is less than $600 \mathrm{~kJ} / \mathrm{d}$. In patients with cirrhosis of the liver, the differences between intake and
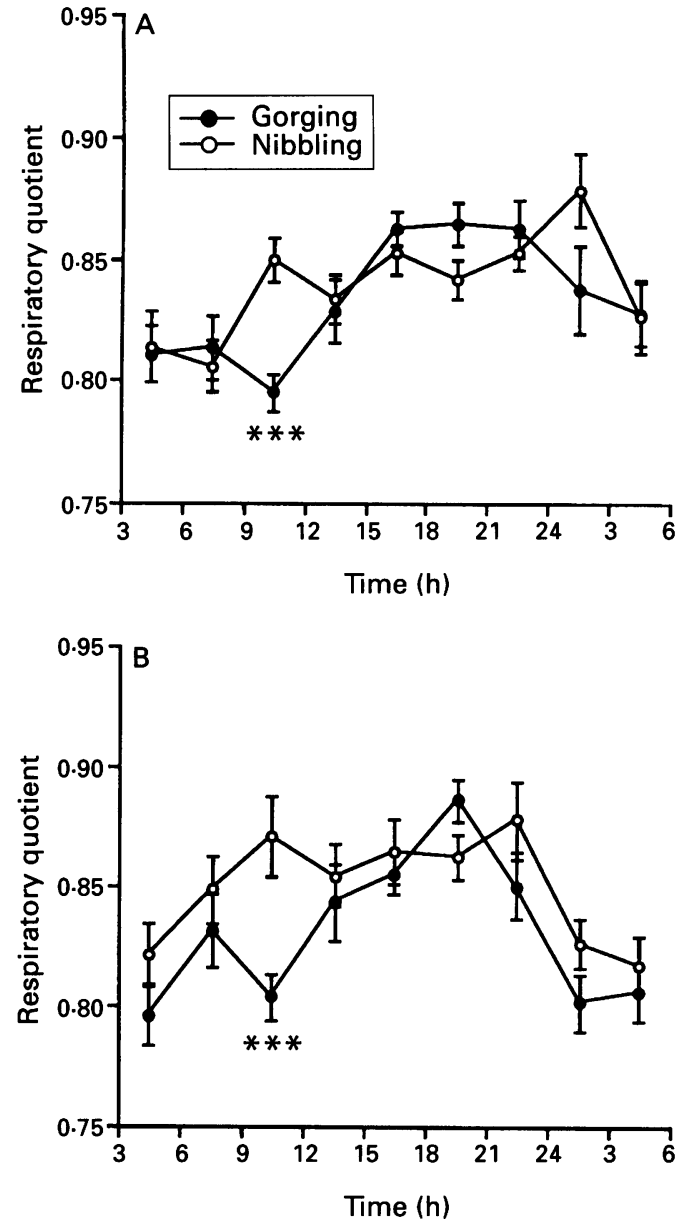

Figure 1: Fluctuation of the respiratory quotient over three hour intervals, from 3.00 on day 2 to 6.00 on day 3 , on the gorging and nibbling diet pattern. (A) Patients with cirrhosis of the liver $(n=7)$; $(B)$ healthy young adults $(n=13)$. Statistical significance gorging $\mathrm{v}$ nibbling pattern: $\star \star \star p<0.001$.

expenditure were $-589(498) \mathrm{kJ} / \mathrm{d}$ for the gorging and $-391(467) \mathrm{kJ} / \mathrm{d}$ for the nibbling patterns. At an individual level differences were higher, but this difference was highly reproducible between the two meal frequency patterns thus allowing further comparison.

\section{BODY MASS AND BODY COMPOSITION}

During the stay in the respiration chamber, the body mass of the cirrhotic patients fell by $0 \cdot 2$ $(0 \cdot 1) \mathrm{kg}$ on the gorging pattern (all subjects except subject 4 and $8 ; \mathrm{p}=0.08$ ) and by 0.3 $(0 \cdot 1) \mathrm{kg}$ on the nibbling pattern (all subjects except subject 4 and $8 ; p<0.05$ ). There was no effect of feeding frequency on loss of body mass. The fat free mass was significantly lower in women $(49.1(2.4) \mathrm{kg})$ than men $(60.5(1.2)$ $\mathrm{kg})(\mathrm{p}<0.01)$. The fat mass and percentage body fat (\% fat) were not significantly different between women (fat mass: $17 \cdot 3(3.6) \mathrm{kg}$; \% fat: $25 \cdot 6(4 \cdot 1))$ and men (fat mass: $13.6(2 \cdot 9)$ $\mathrm{kg}$; \% fat: $17 \cdot 9(3 \cdot 1))$.

In the healthy adult controls body mass changed $0(0 \cdot 1) \mathrm{kg}$ during the gorging pattern (not significantly different from zero) and -0.2 $(0 \cdot 1) \mathrm{kg}$ during the nibbling pattern (not significantly different from zero). Repeated measures ANOVA showed that there was no effect of feeding frequency on the change in body mass. 


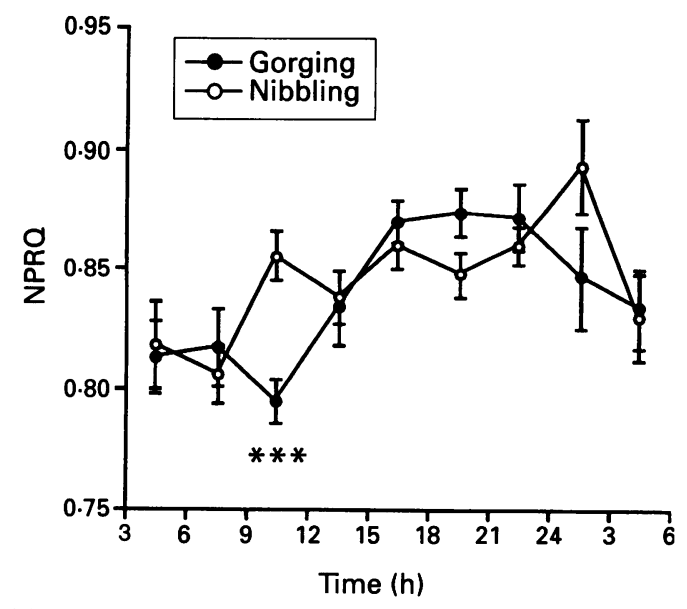

Figure 2: Fluctuation of the non-protein respiratory quotient (NPRQ) over three hour intervals for patients with liver cirrhosis on the gorging and nibbling diet pattern $(n=7)$. Statistical significance gorging $\mathrm{v}$ nibbling pattern: $\star \star \star p<0.001$.

\section{ENERGY EXPENDITURE}

Twenty four hour energy expenditure in the cirrhotic patients was not significantly different between the gorging $(9191(605) \mathrm{kJ} / \mathrm{d})$ and the nibbling patterns $(9146(580) \mathrm{kJ} / \mathrm{d})$. There was no effect of the pattern of food intake on the sleeping metabolic rate, when this was expressed in absolute values (gorging pattern: 6817 (460) kJ/d; nibbling pattern: 7136 (433) $\mathrm{kJ} / \mathrm{d}$ ) or when it was expressed as a percentage of 24 hour energy expenditure (gorging pattern: $74 \cdot 2(1 \cdot 2) \%$; nibbling pattern: $78 \cdot 2$ $(2 \cdot 0) \%)$.

A comparison of energy metabolism between patients with liver cirrhosis and healthy adult controls showed that 24 hour energy expenditure and sleeping metabolic rate (both in absolute values) were not significantly different (Table II). When expressing 24 hour energy expenditure as a multiple of the sleeping metabolic rate, reflecting the level of physical activity in the respiration chamber, it was significantly low for patients with liver cirrhosis $(p<0 \cdot 01)$. The sleeping metabolic rate expressed per $\mathrm{kg}$ body mass, fat free mass, or as a percentage of basal metabolic rate (according to the Harris and Benedict equation) was significantly increased in patients compared with healthy adult controls. Body mass and fat free mass were not significantly different between patients (body

TABLE III Mean intake, oxidation, and balance (=intake-oxidation) of protein, fat, and carbohydrate over 24 hours in patients with liver cirrhosis on the gorging and nibbling pattern. Data are expressed as mean (SEM) g/d

\begin{tabular}{|c|c|c|}
\hline & Gorging pattern & Nibbling pattern \\
\hline \multicolumn{3}{|l|}{ Protein: } \\
\hline Intake & $59.8(3.5)$ & $61 \cdot 1(3 \cdot 2)$ \\
\hline Oxidation & $58.9(5.2)$ & $60.4(5.5)$ \\
\hline Balance & $+0.9(2.8)$ & $+0.7(2.9)$ \\
\hline \multicolumn{3}{|l|}{ Fat: } \\
\hline Intake & $81 \cdot 6(4 \cdot 7)$ & $83 \cdot 1(4 \cdot 3)$ \\
\hline Oxidation & $107 \cdot 0(13 \cdot 0)$ & $101 \cdot 4(10 \cdot 8)$ \\
\hline Balance & $-25 \cdot 4(13 \cdot 2)$ & $-18.3(9 \cdot 3)$ \\
\hline \multicolumn{3}{|l|}{ Carbohydrate: } \\
\hline Intake & $242 \cdot 1(12 \cdot 8)$ & $246 \cdot 1(11 \cdot 7)$ \\
\hline Oxidation & $219.9(12.8)$ & $228.6(14.0)$ \\
\hline Balance & $+22 \cdot 2(4 \cdot 6)^{\star \star}$ & $+17 \cdot 5(16 \cdot 7)$ \\
\hline
\end{tabular}

$\star \star$ Significantly different from zero $(p<0.01)$.

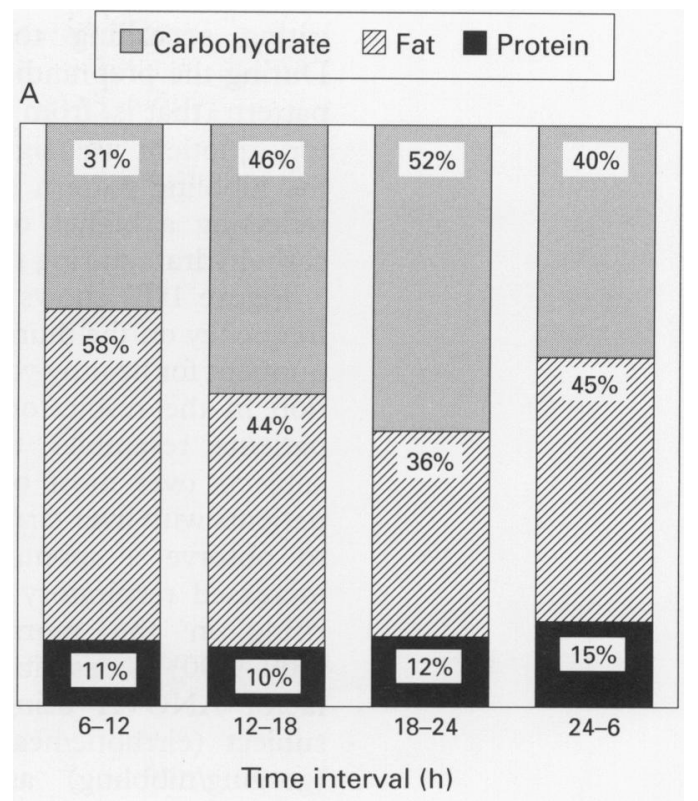

B

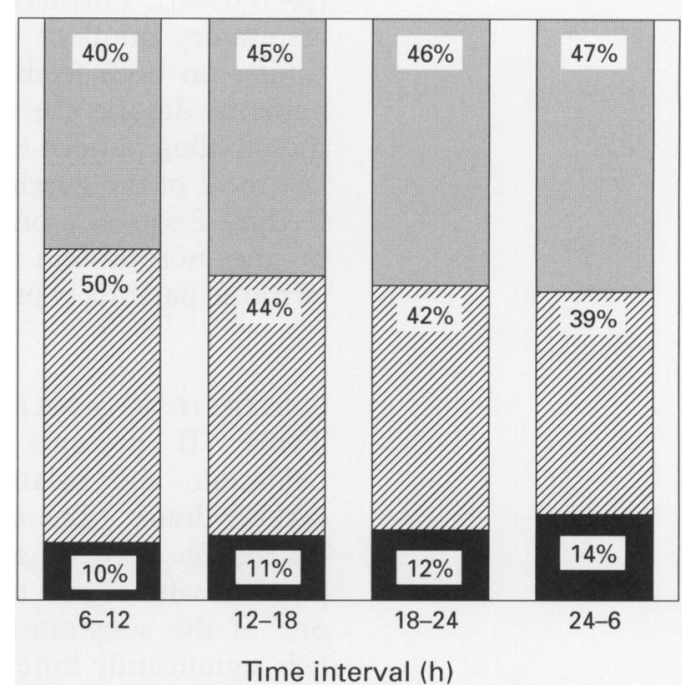

Figure 3: Contribution of protein, fat, and carbohydrate oxidation (\% of energy expenditure) over six hour intervals for patients with liver cirrhosis on the gorging $(A)$ and nibbling (B) patterns $(n=7)$.

mass: $70.4(3.0) \mathrm{kg}$; fat free mass: $54.8(2.5)$ $\mathrm{kg}$ ) and adult controls (body mass: $76 \cdot 8$ (3.9) $\mathrm{kg}$; fat free mass: $58 \cdot 2(1 \cdot 3) \mathrm{kg}$ ).

\section{RESPIRATORY QUOTIENT AND NON-PROTEIN} RESPIRATORY QUOTIENT

In patients with cirrhosis, the 24 hour respiratory quotient was not significantly different between the gorging $(0.84(0.01))$ and the nibbling patterns $(0.84(0.01))$. For both patterns the respiratory quotient was lower than the food body quotient $(=0.86)$, indicating mobilisation of energy from both fat stores. The slightly negative energy balance of the patients on both feeding patterns could be an important cause of this finding. Figure 1(A) presents the diurnal pattern of the respiratory quotient for patients with cirrhosis from the night preceding the second experimental day to the early morning of the third day. There was a considerable fluctuation in the respiratory quotient when 
eating according to the gorging pattern. During the preprandial period on the gorging pattern (that is, from 9.00-12.00) the respiratory quotient was significantly lower than on the nibbling pattern (with breakfast at 7.30), reflecting a higher oxidation ratio of fat to carbohydrate during this period of the day.

Figure 1(B) shows the influence of feeding frequency on the diurnal pattern of respiratory quotient for healthy young adults. The fluctuation in the respiratory quotient for cirrhotic patients resembles the pattern for control subjects over most of the 24 hour cycle. In patients with liver cirrhosis, however, we failed to observe a spontaneous tendency to an increased respiratory quotient at the time of rising in the morning (that is, interval 6.00-9.00) as described for the controls. Two factor ANOVA using the condition of the subject (cirrhotic/healthy) and meal pattern (gorging/nibbling) as dependent variables, showed that this effect was close to significance $(p=0.0586)$. Furthermore, we found that the respiratory quotient during the night is very similar on both feeding patterns for cirrhotic patients, despite the fact that the last meal of the nibbling pattern is 4.5 hours later than the last meal of the gorging pattern. The effect of feeding frequency on the diurnal fluctuation in the non-protein respiratory quotient in cirrhotic patients is presented in Figure 2.

\section{SUBSTRATE METABOLISM}

Table III presents the 24 hour intake, oxidation, and balance of protein, fat, and carbohydrate. There were no significant differences between the gorging and nibbling patterns with regard to oxidation or balance of one of the substrates. Carbohydrate balance was significantly different from zero $(p<0.01)$ for subjects on the gorging pattern.

The diurnal variation in substrate oxidation in cirrhotic patients is presented in Figure 3. Oxidation of protein, fat, and carbohydrate is calculated over six hour intervals and expressed as a percentage of the total energy expenditure during the interval. From $6.00-12.00$, the contribution of carbohydrate to total energy expenditure was significantly lower on the gorging pattern (31 (3)\% $v 40$ (3) $\%$ on the nibbling pattern, $p<0.05)$. During the other time intervals no significant effect of the pattern of food intake on substrate oxidation was observed.

On the nibbling pattern, the contribution of protein, fat, and carbohydrate to the total energy expenditure was fairly constant throughout the day. From 6.00-12.00 we observed a significantly higher fat oxidation compared with nocturnal values (50 (2)\% v 39 $(4) \%, p<0.01)$, despite the fact that subjects ate breakfast at 7.30 .

On the gorging pattern, however, there was a noticeable fluctuation in the nature of substrate being oxidised. Here, during the preprandial period (that is, from 6.00-12.00), energy was mostly derived from fat oxidation (58 (4)\%), and throughout the day less fat and more carbohydrate was being oxidised
(6.00-12.00 v 12.00-18.00: $\mathrm{p}<0.01$; 6.00-12.00 $v$ 18.00-24.00: $\mathrm{p}<0.001)$. From 24.00-6.00, the contribution of protein to total energy expenditure is becoming more important in the gorging pattern (24.00-6.00 $v$ 6.00-12.00: $\mathrm{p}<0.05 ; 24.00-6.00 v$ 12.00-18.00: $\mathrm{p}<0.01$ ); oxidation of fat and carbohydrate is increasing and decreasing respectively, to reach preprandial values. Comparison of substrate oxidation values between patients with cirrhosis and healthy controls was not justified, because the patients with cirrhosis consumed relatively less protein and more carbohydrate than the controls.

\section{Discussion}

One of the aims of this study was to investigate whether energy metabolism in patients with liver cirrhosis is different from that in healthy controls. There are conflicting data on resting energy expenditure in patients with cirrhosis. Focusing on measurements of the resting metabolic rate in patients with cirrhosis compared with healthy controls, no difference in the rate was observed by several investigators when it was expressed in absolute values, as a function of total body surface area, or per $\mathrm{kg}$ body mass. ${ }^{2-7}$ When the resting metabolic rate was related to urinary creatinine excretion as an estimate of lean body mass, it was increased in cirrhotic patients compared with controls. $^{2-4}$ The resting metabolic rate per kg fat free mass was not found to be different between cirrhotic patients and controls in one study in which the fat free mass was assessed by skinfold thickness ${ }^{7}$; others found the resting metabolic rate/kg fat free mass to be significantly higher in patients with cirrhosis when the fat free mass was assessed by bioelectrical impedance. ${ }^{4}$

In the present study we observed a significantly increased sleeping metabolic rate per kg body mass or fat free mass in patients with cirrhosis (Table II). Because 24 hour energy expenditure was similar in patients and controls, this suggests that energy expenditure during the active hours of the day was decreased. This could either be due to a reduced level of physical activity of the patients or to lowering of the energy costs of processing food, that is, the diet induced thermogenesis. Recently, Campillo et al ${ }^{27}$ described a delayed and blunted increment of energy expenditure after a meal in patients with cirrhosis.

With regard to the influence of the pattern of food intake on substrate metabolism, a gorging pattern of intake is associated with a greater fluctuation of the respiratory quotient for both, patients with cirrhosis and controls. During the period of rising in the morning, the respiratory quotient in cirrhotic patients is similar to nocturnal values, in contrast to the control subjects, in whom it tended to increase after rising. This tendency to an increased respiratory quotient observed from $6.00-9.00$ in controls is explained by an increase in carbohydrate utilisation due to muscle glycogen oxidation during the arousal 
process. ${ }^{28}$ In cirrhotic patients it was found that the muscle glycogen content after an overnight fast was within the normal range ${ }^{29}$ and comparable to that in control subjects. ${ }^{30} 31$ One of these studies also examined the muscle glycogen content and the activity of glycogen synthase after a glucose clamp. ${ }^{30}$ They reported less glycogen deposition in muscle during clamp in cirrhotic patients than in control subjects. Furthermore, a decreased activity of glycogen synthase was observed at the end of the clamp in patients with cirrhosis. Selberg et $a^{29}$ reported a positive correlation between fasting muscle glycogen content and basal respiratory quotient, early postabsorptive quotient (five to six hours after a standardised breakfast), and post-exercise respiratory quotient. This finding may suggest that the muscle glycogen content in the patients in the present study is decreased, because even after a late evening meal containing $20 \%$ of the total energy intake and an overnight fast of nine hours, as in the nibbling pattern, a rise in respiratory quotient during the arousal process is not observed. Besides the studies concerning the muscle glycogen concentration in cirrhotic patients, information on the mobilisation of glycogen would also be favourable.

Another important finding in cirrhotic patients was the fact that the nocturnal respiratory quotient values and the values at rising were similar on both feeding patterns, although the first response to a late evening meal was a rise in the respiratory quotient (24.00-3.00) reflecting a temporary higher oxidation ratio of carbohydrate to fat. Because of the reduced glycogen stores in the liver of cirrhotic patients, ${ }^{32}$ energy must be derived from other substrate sources (that is, protein or fat) when fasting is proceeding. Swart et al ${ }^{33}$ studying protein turnover in patients with cirrhosis, suggested an early onset of gluconeogenesis from amino acids at night, resulting in extra amino acid loss and hence a depletion of tissue protein stores. Our data confirm Owen's findings that after an overnight fast of 10-12 hours, energy is mostly derived from fat. ${ }^{5}$

With regard to 24 hour oxidation of protein, fat, and carbohydrate, no significant effects of the pattern of food intake were observed. On the gorging pattern, carbohydrate oxidation was significantly lower than carbohydrate intake, resulting in a positive carbohydrate balance (Table III). We suggest that patients with liver cirrhosis have some difficulty in handling two large meals, each containing 50\% of the total energy intake.

Dividing the day in six hour intervals to investigate the diurnal variation in substrate oxidation, showed a noticeable fluctuation in the nature and amount of substrate oxidised on the gorging pattern (Fig 3(A)). Nocturnal protein oxidation (24.00-6.00) was significantly increased when compared to the morning episode $(6.00-12.00 ; \mathrm{p}<0.05)$ and the afternoon $(12.00-18.00 ; \mathrm{p}<0.01)$. In the nibbling pattern there was no significant change in protein oxidation throughout the day. These findings support the hypothesis of Swart et $a l^{33}$ that, due to the small and inade- quate glycogen stores in the liver of cirrhotic patients, gluconeogenesis from amino acids will take place during overnight fasting. A nibbling pattern of food intake including a late evening meal possibly reduces nocturnal amino acid breakdown and hence improves nitrogen balance. ${ }^{18}$

During the period from 6.00-12.00, the contribution of fat oxidation to total energy expenditure in cirrhotic patients was $58 \%$ in the gorging pattern and as high as $50 \%$ in the nibbling pattern where the patients consumed a breakfast of $20 \%$ of daily energy intake at 7.30. This would suggest that even after a short term fast of nine hours, fat is used as an alternative fuel for glucose, which cannot be provided in sufficient amounts because of the depleted glycogen stores in the liver. These results are in accordance with the conclusions of other studies on substrate metabolism in cirrhotic patients, revealing that the period to reach a catabolic state (in which most of the energy is derived from fat) is much shorter in patients with cirrhosis of the liver. ${ }^{35} 34$

1 Bosari S, Marradi C, Chiara O, Bevilacqua G, Nespoli A. Energy expenditure in cirrhotic patients. In: Kleinberger G, Ferenci P, Riederer P, Thaler H, eds. Advances in hepatic encephalopathy and urea cycle diseases. Basel: hepatic encephalopathy

2 Shanbhogue RIK, Bistrian BR, Jenkins RL, Jones C, Benotti P, Blackburn GL. Resting energy expenditure in patients with end-stage liver disease and in normal population. F Parenter Enteral Nutr 1987; 11: 305-8.

3 Schneeweiss B, Graninger W, Ferenci P, Eichinger S, Grimm G, Schneider B, et al. Energy metabolism in patients with acute and chronic liver disease. Hepatology 1990; 11: 387-93.

4 Müller MJ, Fenk A, Lautz HU, Selberg O, Canzler H, Balks $\mathrm{HJ}$, et al. Energy expenditure and substrate metabolism in ethanol-induced liver cirrhosis. Am F Physiol 1991; 260: E338-44.

5 Owen OE, Trapp VE, Reichard GA, Mozzoli MA, Moctezuma J, Paul P, et al. Nature and quantity of fuels consumed in patients with alcoholic cirrhosis. $\mathcal{F}$ Clin Invest 1983; 72: 1821-32.

6 Jhangiani SS, Agarwal N, Holmes R, Cayten CG, Pitchumoni CS. Energy expenditure in chronic alcoholics with and without liver disease. Am F Clin Nutr 1986; 44: 323-9.

7 Merli M, Riggio O, Romiti A, Ariosto F, Mango L, Pinto G, et al. Basal energy production rate and substrate use in stable cirrhotic patients. Hepatology 1990; 12: 106-12.

8 Nielsen K, Kondrup J, Martinsen L, Dossing H, Stilling B. Energy expenditure measured by the doubly-labelled water method during hyperalimentation of malnourished patients with liver cirrhosis. Clin Nutr 1992; 11 (suppl): 7 .

9 Müller MJ, Lautz HU, Plogmann B, Bürger M, Körber J, Schmidt FW. Energy expenditure and substrate oxidation in patients with cirrhosis: The impact of cause, clinical staging and nutritional state. Hepatology 1992; 15: 782-94.

10 Fábry P, Fodor J, Hejl Z, Braun T, Zvolánková K. The frequency of meals: Its relationship to overweight, hypercholesterolaemia, and decreased glucose tolerance. Lancet 1964; ii: 614-5.

11 Terpstra J, Hessel LW, Seepers J, Van Gent CM. The influence of meal frequency on diurnal lipid, glucose and cortisol levels in normal subjects. Eur $\mathcal{F}$ Clin Invest 1978; 8: $61-6$.

12 Dallosso HM, Murgatroyd PR, James WPT. Feeding frequency and energy balance in adult males. Hum Nutr: Clin Nutr 1982; 36C: 25-39.

13 Irwin MI, Feeley RM. Frequency and size of meals and serum lipids, nitrogen and mineral retention, fat digestibility, and urinary thiamine and riboflavin in young women. Am f Clin Nutr 1967; 20: 816-24.

14 Young CM, Hutter LF, Scanlan SS, Rand CE, Lutwak L, Simko V. Metabolic effects of meal frequency on normal young men. $\mathcal{F A m}$ Diet Assoc 1972; 61: 391-98.

15 Debry G, Rohr R, Azouaou R, Vassilitch I Mottaz G. Ponderal losses in obese subjects submitted to restricted diets differing by nibbling and by lipid and carbohydrate. In: Apfelbaum $M$, ed. Energy balance in man. Paris: Masson, 1973: 305-10.

16 Fábry $P$. Food intake pattern and energy balance. In: Apfelbaum M, ed. Energy balance in man. Paris: Masson,

17 Verboeket-van de Venne WPHG, Westerterp KR. Influence 
of the feeding frequency on nutrient utilization in man: Consequences for energy metabolism. Eur $\mathcal{f}$ Clin Nutr 1991; 45: 161-9.

18 Swart GR, Zillikens MC, Van Vuure JK, Van den Berg JWO. Effect of a late evening meal on nitrogen balance in patients with cirrhosis of the liver. $B M F$ 1989; 299: 1202-3.

19 Verboeket-van de Venne WPHG, Westerterp KR, Kester ADM. Effect of the pattern of food intake on human energy metabolism. Brf Nutr 1993; 70: 103-15.

20 Harris JA, Benedict FG. A biometric study of basal metabolism in man. Washington DC: Carnegie Institute Publication 279, 1919: 1-266.

21 Flatt JP. Dietary fat, carbohydrate balance, and weight maintenance: Effects of exercise. Am $\mathcal{F}$ Clin Nutr 1987; 45: maintenance

22 Schoeller DA, Jones PJH. Measurement of total body water by isotopic dilution: A unified approach to calibrations. In: Ellis KJ, Yasumura S, Morgan WD, eds. In vivo body composition studies. London: Institute of Physical Science in Medicine, 1987: 131-6.

23 Schoffelen PFM, Saris WHM, Westerterp KR, Ten Hoor F. Evaluation of an automatic indirect calorimeter for measurement of energy balance in man. In: Van $\mathrm{Es} A \mathrm{AH}$, ed. Human energy metabolism: Physical a diture measurement in epidemiological research based upon diture measurements in epidemiological research based upon direct and indirect calorimetry. Wageningen: Nutrition

24 Weir JB de V. New methods for calculating metabolic rate with special reference to predict protein metabolism. f Physiol 1949; 109: 1-9.

25 Jéquier E, Acheson K, Schutz Y. Assessment of energy expenditure and fuel utilization in man. Annu Rev Nutr 1987; 7: 187-208.
26 Garrows IS. Energy balance and obesity in man. Amsterdam: North Holland Publishing Company, 1974.

27 Campillo B, Bories P-N, Devanlay M, Sommer F, Wirquin E, Fouet P. The thermogenic and metabolic effects of $\mathrm{E}$, Fouet P. The thermogenic and metabolic effects of
food in liver cirrhosis: Consequences on the storage of food in liver cirrhosis: Consequences on the storage of
nutrients and the hormonal counterregulatory response. Metabolism 1992; 41: 476-82.

28 Lean MEJ, James WPT. Metabolic effects of isoenergetic nutrient exchange over 24 hours in relation to obesity in women. Int 7 Obes 1988; 12: 15-27.

29 Selberg O, Radoch E, Walter GF, Schwarze M, Müller MJ. Muscle glycogen content in patients with liver cirrhosis. Clin Nutr 1992; 11 (suppl): 6.

30 Kruszynska Y, Williams N, Perry M, Home P. The relationship between insulin sensitivity and skeletal muscle enzyme activities in hepatic cirrhosis. Hepatology 1988; 8: $1615-9$

31 Möller P, Berström J, Fürst P, Hellström K. Muscle biopsy studies in patients with moderate liver cirrhosis with special reference to energy-rich phosphagen and electrolytes. Scand $f$ Gastroenterol 1984; 19: 267-72.

32 Owen OE, Reichle FA, Mozzoli MA, Kreulen T, Patel MS, Elfenbein IB, et al. Hepatic, gut, and renal substrate flux rates in patients with hepatic cirrhosis. $\mathcal{f}$ Clin Invest 1981; 68: $240-52$.

33 Swart GR, Van den Berg JWO, Wattimena JLD, Rietveld T, Van Vuure JK, Frenkel M. Elevated protein requirements in cirrhosis of the liver investigated by whole body protein in cirrhosis of the liver investigated by whole

34 Marchesini G, Bianchi GP, Zoli M, Checchia GA. Glucose homeostasis in cirrhosis. In: Tygstrup N, Orlandi F, eds. Cirrhosis of the liver: Methods and fields of research. Amsterdam: Elsevier, 1987: 165-76. 